\title{
The effects of recoding and presentation format on recency and suffix effects
}

\author{
SUSAN KARP MANNING, LAURA KOEHLER, and SCOTT HAMPTON \\ Hunter College and the Graduate School of the City University of New York, New York, New York
}

\begin{abstract}
The primary linguistic theory of Shand and Klima (1981) hypothesizes that stimuli that cannot be directly processed without recoding are not in the primary linguistic mode of the subject and thus should lead to lesser recency and associated suffix effects. In three experiments, different normal hearing subjects learned to pair American Sign Language (ASL) stimuli, visual "quasivocables" (QVs), word-like letter strings, and auditory QVs with common English words. In the first experiment, the subjects were given sequences of ASL or QV stimuli and required to recall the associated words in strict serial order. In two other experiments involving auditory and visual presentation, respectively, subjects who had never been given paired associate training were required to recall the English words that had previously been associated with the ASL and QV stimuli, in a standard suffix paradigm. The results showed recency and suffix effects to be present only with auditorily presented QVs and words. Contrary to the predictions of the primary linguistic hypothesis, greater recency and larger suffix effects were present with the auditory QVs than with the auditory words, although the QVs were not primary linguistic and the task involved forced recoding. Previous results showing recency with ASL stimuli in normal subjects were not replicated. It is concluded that recency and suffix effects are not related either to the primary linguistic mode of the subject or to stimulus recoding, as we and Shand and Klima have defined them.
\end{abstract}

Recency may be defined as the superior recall of a final item as compared with earlier items. Auditory stimuli tend to lead to greater recency than visual stimuli do. A suffix has been defined as an extra not-to-be-recalled item appended onto a sequence. When stimuli are presented auditorily, rather than visually, the presence of a withinmodality suffix tends to reduce or eliminate recency. This reduction is known as the suffix effect (see Crowder \& Morton, 1969).

For years, the standard theory used to explain these effects was that of Crowder and Morton (1969), who postulated the presence of relatively long-lived auditory and relatively short-lived visual sensory traces. Recency was explained by the subject's access to the extra information available in auditory as opposed to visual traces. This information aided in the recall of the final auditory but not the final visual item. The suffix blocked these traces, thus

This research was supported in part by a grant from The City University of New York PSC-CUNY Research Award Program to Susan Karp Manning. Some of the experiments in this paper were presented in Seattle at the annual meeting of the Psychonomic Society, in November 1987. We wish to thank Betsey S. Silverstein, Elizabeth Shofner, Diana Vila, and John W. Lango for help with various aspects of the project. We also wish to thank Robert Greene, Jim Nairne, Robert Proctor, and one anonymous individual for their helpful reviews. Experiments 1, 2, and 4 were a senior honors project by Laura Koehler under the sponsorship of the senior author. Experiments 3 and 5 were performed as part of a graduate-level independent study project by Scott Hampton, also under the sponsorship of the senior author. Reprint requests should be sent to Susan Karp Manning, Department of Psychology, Hunter College, 695 Park Avenue, New York, NY 10021, or bitnet to SKMHC@CUNYVM. leading to the auditory suffix effect. Since visual sensory traces were too short-lived to be useful, they were not affected by visual suffixes.

However, recent work has presented both challenges to Crowder and Morton's (1969) theory and (of greater interest in this paper) exceptions to the auditory specificity of recency and suffix effects that this theory assumes. One exception that is most difficult to interpret involves the large body of data showing the presence of recency and suffix effects for lipread (e.g., see Campbell \& Dodd, 1980) and mouthed stimuli (e.g., see Campbell, Garwood, \& Rosen, 1988; Greene \& Crowder, 1984), which are not auditory. Additionally, lipread suffixes, which are visual, produce decrements in recency on auditory sequences (e.g., see Manning, 1987; Spoehr \& Corin, 1978).

A second exception to the auditory specificity of these effects involves American Sign Language (ASL), which is visual in modality. When ASL signs are presented for recall to profoundly and congenitally deaf, fluent users of ASL, recency (Krakow \& Hanson, 1985; Shand \& Klima, 1981) and suffix effects (Shand \& Klima, 1981) are reported. Additionally, Campbell, Dodd, and Brasher (1983) taught a small set of ASL signs to high school students with normal hearing and reported large recency effects.

How might lipread and ASL stimuli differ from more standard visual stimuli? One possibility, suggested first by Campbell and Dodd (1980), is that in common with most auditory stimuli, the lipread and ASL stimuli change over time rather than remain static. However, whether stimuli are changing state or not is apparently not a good 
predictor of recency and suffix effects. Data reported by Crowder (1986), using visual stimuli presented on a computer screen that changed over time, by Manning (1980), using visual stimuli presented by moving a pen end over a card without making a mark, and by Manning and Gmuer (1985), using the visual display of the Optacon (a reading aid for the blind that presents a series of moving dots similar to the Times Square news display), do not show recency. In addition, Shand and Klima (1981) reported recency and suffix effects with still pictures of ASL signs presented to congenitally deaf fluent users of ASL, suggesting that some visual stimuli that are not changing state may produce recency and suffix effects.

However, questions remain about whether the recency shown by Shand and Klima (1981) and Krakow and Hanson (1985) and the suffix effects shown by Shand and Klima (1981) with both still and moving ASL stimuli are the same as those found in the standard suffix paradigm, which requires strict serial recall. These researchers used a modified free recall procedure, in which a subject given serially presented stimuli was permitted to output the stimuli in any order, as long as presentation order was indicated.

The idea that the free recall procedure rather than the presentation format may be leading to the recency and suffix effects obtained is suggested in a study by Cohen (1972). In this experiment, U-shaped recall curves and small atypical suffix effects, which do not reduce recency to the degree usually found with auditory stimuli, were reported with pictures. The serial recall curves and suffix effects obtained by Shand and Klima (1981) with both moving and still ASL signs (which are similar to pictures) appear to be very much like those of Cohen.

In an effort to test directly the effects of recall method, two studies were performed in our laboratory (Manning \& Schreier, 1988), also using pictures. In Experiment 1, modified free recall was used, and in Experiment 2, strict serial recall was used. In Experiment 1, the results of Cohen were replicated. In Experiment 2, recency and suffix effects disappeared entirely. Since both Shand and Klima (1981) and Krakow and Hanson (1985) used modified free recall procedures, and since the recency and suffix effects reported were similar to the ones obtained with pictures under the same recall procedure, the question arises as to whether the ASL work with the deaf is a true exception to the usual visual-auditory differences in recency and suffix effects. This will have to be determined empirically in studies of deaf subjects.

We also question the previously mentioned results of Campbell et al. (1983) with ASL signs taught to normal hearing junior high school students. Although using a strict serial recall procedure, Campbell et al. report large recency effects. These data may be questioned, because they fail to fit the general findings with respect to the absence of recency and suffix effects in the strict serial recall of visual stimuli. In a comprehensive study, consisting of several experiments involving a variety of visual stimuli and conditions, Greene (1987) reported no evidence of recency or suffix effects in any of the conditions. In fact, the only visual stimuli that appear to produce consistent recency and suffix effects are lipread stimuli.

The questions posed above are helpful in delimiting the conditions leading to recency and suffix effects. However, they do not provide answers to the question of what mechanisms might explain recency and suffix effects. In an effort to explain these effects, Shand and Klima (1981) used data obtained from deaf subjects as the basis of a theory positing that greater recency and suffix effects are present in either $a$ or the primary linguistic mode of the subject. They state that stimuli in a primary linguistic mode are "in a form that allows immediate interpretation without recoding into a more primary form. That is, such inputs can be coded at the level of short-term memory without the necessity of being recoded into some code not based on the physical aspects of the input signal" (p. 466). They further state that " (a) any form that serves as the basis for a primary linguistic code for the subject will show a recency advantage when compared to lists of items that are not in such a form, regardless of the modality of such a system and (b) the recency advantage for primary linguistic input will be diminished by addition of a suffix that consists of a linguistic item from that system, even if the primary linguistic stimuli are not auditory" (p. 466).

\section{Types of Recoding}

Although some of the data underlying Shand and Klima's (1981) theory may be problematic, the theory employs concepts worth exploring as explanations of recency and suffix effects. One is the concept of "recoding." Although this concept has been used in the literature frequently, we believe it has never been clearly developed. In the current paper, an attempt will be made to clarify distinctions among types of recoding. Then an attempt will be made to determine what the relation is between this concept and recency and/or suffix effects. Finally, these concepts will be related to the theory postulated by Shand and Klima.

Shand and Klima (1981) state that stimuli in a primary linguistic mode can be interpreted without recoding into a representation based directly on the physical signal. One can argue that the formation or "use" of a representation in itself requires recoding. However, if we assume that the relation between stimuli and associated representations can differ in involving greater or lesser transformations of the initial input to form the representation, distinctions can be made between types of recoding. We will consider only three types, which will be referred to as Types 1, 2, and 3, the lower numbers referring to lesser degrees of stimulus transformation in the representation.

Type 1 recoding. This type involves a minimal amount of change in the stimulus to form a representation. Type 1 recoding should be present with auditory stimuli for normal hearing subjects and perhaps with ASL for those fluent in this communication format. It could, conceivably, also occur with a nonword or any other stimulus 
that can be "directly" represented or processed. For example, a nonsense word presented auditorily might not be recoded and not be associated with a primary linguistic stimulus. Shand and Klima (1981) specifically limit their theory to stimuli in linguistic or linguistic-like systems. Type 1 recoding, then, includes primary linguistic stimuli, as defined by Shand and Klima. However, because it also includes stimuli that are not primary linguistic, but that may still be processed directly, the definition presented here is both broader and different in conceptualization.

Type 2 recoding. The second type of recoding involves stimuli presented in a modality that can be directly processed. However, the recoding involves a within-modality change, or an addition to the stimuli, and thus a change in the associated representation. An example might be the translation or recoding occurring in an auditorily presented poorly learned second language or possibly also with difficult or unfamiliar words in the subject's native language. Following the view of Shand and Klima (1981), a similar situation should occur if a fluent user of ASL learns a new sign. Such recoding may also be necessary if semantic processing is to occur and may occur automatically when poorly learned words (or signs) are presented in a foreign or even a native language. Shand and Klima specifically predict that recency will be reduced or eliminated in the auditorily presented second language situation.

Applying this reasoning to other types of stimuli, it seems logical to assume that the prediction also extends to a nonsense syllable, unknown word, or unknown sign, if any form of association or recoding occurs. Shand and Klima (1981), however, have not made specific predictions in these situations, which are outside the realm of linguistic or linguistic-like stimuli. They are included here under Type 2 recoding.

Shand and colleagues support their predictions with non-primary linguistic stimuli in two sets of studies available in abbreviated form. In the first study, Shand and Elman (1982) used native speakers of either English or Spanish, who were learning the other language. Subjects asked to recall numbers, auditorily presented in both languages, showed greater recency for numbers in the native as opposed to the other language. In the second study, Tartter and Shand (1980) found that native English speakers showed diminished recency when recall for auditorily presented pig latin was compared with that for auditorily presented English words.

However, a similar experiment was performed in this laboratory before we became aware of the studies described above. It yielded different results, which led us to question whether stimuli that are not part of a subject's primary linguistic system will show lesser recency in recall than stimuli that are. Using native speakers of English, who had studied but were not fluent in French, we were unable to find reliable differences in recency when recall for English and French words was compared. The experiment further revealed slightly less recency for the English words, according to both standard and normalized scoring (Manning, Silverstein, \& Schreier, 1989).

A second experiment (also Manning et al., 1989) involved the same stimuli and non-native speakers of English who had never studied French. In this experiment, no significant differences in recency were present in the English and French conditions. However, of greater importance, recency was again slightly greater for the unknown French words for the subjects in the second experiment than for the English words for the native speakers of English in the first experiment.

Although the Manning et al. (1989) studies are inconsistent with the hypothesis that Type 2 recoding, as defined here, leads to a reduction in recency when compared with Type 1 recoding, they are not definitive. This is because it is not certain that subjects engage in Type 2 recoding in either the second language or the unknown language conditions. The view that subjects are engaged in Type 2 recoding is supported by the finding that overall performance-that is, performance at all positions in serial recall-is significantly reduced with both the second language and the unknown language stimuli, as compared with the primary language stimuli. However, although unlikely, it is possible that Type 1 recoding is occurring, and that subjects are "directly" processing (i.e., not translating or recoding) unfamiliar representations of both the second language French and the unknown French stimuliand that relative unfamiliarity is the source of the performance reduction. Thus, although the Manning et al. (1989) experiments refute the primary linguistic aspect of the Shand and Klima (1981) theory, because recency is at least equivalent for primary linguistic and nonprimary linguistic stimuli, they do not completely refute the hypothesis that Type 2 recoding reduces recency, because recoding is not assured.

Type 3 recoding. The third type of recoding is present when the representation produced by a stimulus must undergo either a complete or a partial shift in format for processing to occur. Such a format shift may involve either a between-modality change or a within-modality change. An example of a between-modality change in a representation might involve alphanumeric stimuli presented visually to normal hearing subjects. Three examples of within-modality changes in representations follow: The first might occur when alphanumeric characters are presented to profoundly congenitally deaf subjects. The representation formed might involve ASL or some other visual format. The second might occur when a normal hearing subject, fluent in ASL, forms a representation in ASL. The third example might involve a nondeaf subject hearing the sound of a bell and forming a representation involving the phonemes making up the word bell.

The important point is that, in within-modality format changes, the physical form underlying the representation differs from the physical stimulus, although it remains in the same modality. This differs from Type 2 recoding, in which the representation produced by the stimuli maintains the same format in both the original and the recoded 
forms (both might, for example, involve mainly auditory representations of phonemes).

Between-modality Type 3 recoding corresponds to that postulated by Shand and Klima (1981) for alphanumeric visual stimuli with hearing subjects. A considerable body of literature is consistent with the view that at least some stimuli are recoded in this way. Visually presented letters of the alphabet more frequently show auditory confusions (e.g., see Conrad, 1964) than auditorily presented stimuli show visual confusions, thus suggesting an auditory component in the representation. As for recency and suffix effects, data involving most visual stimuli seem to support the views of Shand and Klima. Most experiments involving the presentation of alphanumeric visual stimuli to normal hearing subjects appear not to have led to recency or suffix effects (e.g., Crowder \& Morton, 1969; Greene, 1987).

Further evidence that other visual stimuli may lead to auditory representations is provided by work with pictures. Many studies have suggested that the representation of a picture may involve both visual and auditory components (see, for example, Paivio, 1969, 1971; and Paivio, Rogers, \& Smythe, 1968, for descriptions of the dual coding hypothesis). As we have mentioned previously, with a strict serial recall procedure in which the subject is shown pictures in sequential order and required to write the names of the objects that the pictures portray, recency and suffix effects are not present (Manning \& Schreier, 1988). Such a situation can be classified as Type 3 between-modality recoding, if the dual coding hypothesis is correct and the representation contains an auditory component.

Such a task fits the definition of Type 3 within-modality recoding, if the representation is orthographic and does not contain an auditory component. Further evidence that Type 3 within-modality recoding does not lead to recency and suffix effects is provided by Shand and Klima (1981), in a study in which deaf subjects given orthographically presented letters did not show a recency or suffix effect in recall. However, as mentioned previously, the methodology of this study may be questioned, because it involved modified free recall.

Type 3 recoding may be more complex. An example would be the pairing of visually presented words in an unknown language with visually presented words in a known language. Since both elements of the representation probably contain auditory components, if the Shand and Klima (1981) view is correct, one would predict that such tasks would not produce recency or suffix effects.

\section{Research Goals}

Five experiments were performed to examine various aspects of recency and suffix effects. These experiments were performed with three interrelated, specific goals. The first was to delimit the situations producing recency and suffix effects, by attempting a partial replication of the work with ASL in normal hearing subjects. The second was to clarify the role of recoding, as we have de- fined it, in these phenomena. The third was to attempt to make a clear-cut test of the implications of the primary linguistic hypothesis of Shand and Klima (1981).

\section{EXPERIMENT 1}

Experiment 1 is a partial replication of the study by Campbell et al. (1983), who reported recency in the recall of newly learned ASL signs using normal hearing junior high school students as subjects. As stated above, these data do not fit either the general findings with visual stimuli or the predictions of Shand and Klima (1981). In Experiment 1, as in Campbell et al. (1983), subjects were required to learn to pair each ASL sign with a written English word and then asked to recall the words in strict serial order. We also used several suffix conditionsunlike Campbell et al.

Use of the previously presented classification system means that the task should represent Type 3 recoding. Since the presentation format is unusual and not frequently studied, no data comparable to that for spoken, orthographic, or pictorial stimuli exists as to the format of the representation. Thus, it is not clear whether the representation does or does not contain an auditory component, whether it is visual, or whether it is both visual and orthographic. Regardless of these factors, the situation generates an example of either within- or betweenmodality Type 3 recoding, because it involves a forced change in format in the representation. A subject must at the very least connect an ASL sign to a printed word.

\section{Method}

Subjects. The subjects were 15 Hunter College students whose first language was English. All had normal hearing and were unfamiliar with ASL. Five subjects were eliminated for not following directions.

Apparatus. Stimuli, produced by a female fluent in ASL, were recorded on a Sony videocassette recorder (Model VO-2610). The stimuli were presented to the subjects on a JVC color monitor (Model 7860 UM).

Stimulus Materials and Experimental Design. ASL signs to be used in constructing lists and as the suffix were chosen with the assistance of two deaf individuals who were fluent in ASL. All signs were nouns with four-letter English translations. They were chosen so as to be both well-known by the deaf community and readily distinguishable visually. As far as was known, each had only one unambiguous meaning in ASL. The English translations for the signs making up the lists were: TREE, HOME, NAME, FACE, BIRD, ROAD, and TIME. The suffix was the sign for the word STAR.

Thirty-five sequences were constructed, with each of the seven "list" signs appearing once in each sequence. Sequences ended with one of five suffixes arranged in a random block design. The suffixes were: the ASL sign for STAR, the word STAR printed on an index card, the word STAR spoken, the word STAR mouthed (no sound emitted), and a blank card (control).

The sequences, signed at a rate of one sign every $2 \mathrm{sec}$, were videotaped, with the camera showing the upper torso of the signer against a grey background. A 20 -sec period was left after each sequence, during which the signer was still, but remained in view.

Procedure. The subjects were told that they would be learning to recognize eight ASL signs that would be utilized in a subsequent 
recall task. All instructions and communication took place in written form, in order to permit eventual comparisons between the performances of normal and deaf subjects.

To teach the meaning of the ASL signs, the experimenter demonstrated each sign and then pointed to its English equivalent among a group of displayed cards containing the printed English words. Subjects were required to identify correctly all the associated English nouns. Criterion was met when the subject was able to do this correctly on two successive random presentations of the ASL signs.

The subjects were told that they would view a videotape consisting of 35 sequences of the learned signs. On a data sheet containing seven spaces for each trial they were to write the presented sequences. Recall was to be in strict serial order, and backtracking was not permitted. Blank spaces were to be left when an item could not be recalled. Strict serial recall was carefully monitored.

The subjects were told that a version of the word STAR (signed, spoken, mouthed, or printed) or a blank card would appear at the end of each sequence, that it was the signal for recall, and that it should not be recalled. The subjects had $18 \mathrm{sec}$ to write their responses, after which the experimenter tapped them to signal the next trial.

\section{Results and Discussion}

Items in all experiments were scored as correct if and only if they were both correct and appeared in the proper serial position. Statistics reported as significant are reliable at least at the .05 level, unless otherwise noted. Mean number of correct responses for each serial position, for each suffix condition, are seen in Table 1.

Examination of the data in Table 1 shows that performance in the control condition does not replicate the findings of Campbell et al. (1983) in which recency was not only present but also as large as primacy. Instead, it follows trends typical of the visual modality, with large primacy, steadily declining performance to the penultimate item, and a small increase at the final position.

To further clarify the results, a 5 (suffix) $\times 7$ (serial position) analysis of variance was performed. This analysis showed significant effects of serial position $[F(6,84)=$ 64.05, $\left.M S_{\mathrm{e}}=2.47\right]$ and suffix $\times$ serial position $\left[F(24,336)=1.81, M S_{\mathrm{e}}=.99\right]$, due in both cases to the usual serial position effects, when data were summed over several conditions. The effect of suffix was not significant.

Planned Dunnett tests, based on the error term for the suffix $\times$ serial position interaction $(C-E=.79)$, compared each suffix condition to the control at all serial po-

Table 1

Mean Number of Correct Responses as a Function of Serial Position and Suffix Condition in Experiment 1, in Which ASL Signs Were Presented

\begin{tabular}{lccccccc}
\hline \multirow{2}{*}{$\begin{array}{c}\text { Suffix } \\
\text { Condition }\end{array}$} & \multicolumn{7}{c}{ Serial Position } \\
\cline { 2 - 8 } & \multicolumn{1}{c}{2} & \multicolumn{1}{c}{3} & 4 & 5 & 6 & 7 \\
\hline Control & 6.20 & 5.53 & 4.93 & 3.80 & 3.20 & 2.13 & 2.67 \\
ASL & 6.20 & 5.40 & 5.13 & 3.93 & 3.13 & 1.93 & 2.60 \\
Spoken & 5.80 & $4.67^{*}$ & 4.47 & 3.47 & 3.27 & 2.53 & 2.27 \\
Mouthed & 6.00 & 5.67 & 4.00 & 4.07 & 2.80 & 2.47 & 2.53 \\
Printed & 6.20 & 5.73 & 4.27 & 4.47 & 2.60 & 2.00 & 3.13 \\
\hline
\end{tabular}

Note-Maximum performance is 7 in each serial position. *Dunnett test significant $(\mathrm{C}-\mathrm{E}=.79)$. sitions. Only one difference proved significant, as can be seen in Table 1. Such effects are common both in this paradigm and in others such as this one, in which making multiple comparisons is virtually essential for the analysis. Since the effects of suffixes are so frequently at the end of sequences, this single case in a totally nonpredicted location can probably be safely ignored.

The lack of either recency or end-of-sequence suffix effects in a strict serial recall paradigm is consistent with the findings of Greene (1987) and Manning and Schreier (1988) in such suffix paradigms using visual stimuli, and thus, in spite of the lack of replication of Campbell et al. (1983), the results are extremely convincing.

These results also are consistent with the views of Shand and Klima (1981) with respect to the lack of recency and suffix effects in stimuli that are not in the primary linguistic mode of the subject. Finally, in the terminology of this paper, they are consistent with findings that recency and suffix effects do not occur in Type 3 recoding situations.

\section{EXPERIMENTS 2-5}

To determine more about the effects of recoding, four additional experiments were performed. Two, Experiments 2 and 4, were designed to be as similar to Experiment 1 as possible, while varying the presentation format. In both studies, subjects were required to learn a set of paired associates. In each case, the second member of the pair was the same as the translation of the ASL sign and the first member was what we will call a quasivocable (QV). A vocable may be defined as a word construed as a string of sounds or letters apart from its meaning. A QV then is a string of letters that resembles but is not a word. The fact that it is not a word removes it from a subject's primary linguistic realm.

As in the ASL experiment, the subjects were presented with sequences of QVs using the same suffixes as in Experiment 1 , and they were required to recall in writing the associated English words in strict serial order. Experiments 2 and 4 differed from each other in the mode of presentation of the QV. It was visual in the former and auditory in the latter. Experiments 3 and 5 consisted of simple visual and auditory presentation, respectively, of the word stimuli associated with the ASL and QV stimuli.

These four studies answer several questions and test several hypotheses. The first question is whether in serial recall tasks, alphanumeric visual stimuli, hypothesized to involve a complex form of Type 3 recoding, produce serial position curves and suffix effects that are the same as simple, visually presented, word stimuli, hypothesized to involve a simpler form of Type 3 recoding. Comparisons of Experiments 2 and 3 provide an answer to this question.

The second question is whether the predictions of Shand and Klima's (1981) primary linguistic hypothesis are correct with respect to recency and suffix effects. In the terminology of this paper, the question involves asking whether alphanumeric auditory stimuli, involving Type 2 
recoding, produce serial position curves with less recency and smaller suffix effects than stimuli that involve Type 1 recoding. A simple comparison of Experiments 4 and 5 answers this question. Experiment 4, with nonlanguage alphanumeric stimuli (QVs), provides an example of Type 2 recoding. Unlike in previous studies with auditory presentation of nonword stimuli (e.g., Manning et al., 1989; Shand \& Elman, 1982; Tartter \& Shand, 1980), Type 2 recoding was assured because the subjects were required to produce responses based on the recoded as opposed to the original stimulus. Experiment 5, on the other hand, was hypothesized to involve a more direct processing of the stimuli and thus to give an example of Type 1 recoding.

\section{Methods \\ Subjects and Apparatus. Fifteen Hunter College students, who were native speakers of English, participated in each experiment. Five in Experiment 3 and 3 in Experiment 5 were eliminated for not following directions. The same videotaping equipment was used as in Experiment 1.}

Experimental Design, Stimulus Materials, and Procedures. The experimental design in Experiments 2 and 4 was identical to that of Experiment 1, except that each ASL sign was replaced by a QV. The particular QVs used were four letters long. Despite having the same vowel-consonant patterns as the associated paired associates, the QVs contained no consonants in common with these words. In an effort to minimize variability in orthographic representations produced by subjects, an effort was made to construct QVs so that each had only one reasonable spelling. The list of QV $s$ and their paired associates was as follows: HOTE $=$ NAME; LEAL $=$ ROAD; PAFE = HOME; FINT = BIRD MIDE = FACE; PLOO $=$ TREE; SIFE = TIME. So that the recall conditions would be comparable, the words associated with the QVs were the same as the ASL translations.

The suffix was presented in the same five formats as in Experiment 1, except that the QV SNUP replaced STAR as the suffix. This was true for all but the sign condition. In this condition, an ASL-like sign replaced the ASL sign for STAR used in Experiment 1 , so that any deaf subjects in future experiments would not be familiar with its meaning.

The subjects in Experiments 2 and 4 were told that they would be learning to pair eight invented "words" with eight real words, and that the pairing would be utilized in a subsequent recall task. In Experiment 2, the experimenter showed a printed card with the QV on it, whereas in Experiment 4, the experimenter "spoke" the QV and the subject never saw how it was spelled. In both studies, as with the ASL signs in Experiment 1, the experimenter pointed to the English "translation" among a group of displayed cards containing the printed English words. As before, to meet criterion, subjects were required to correctly identify all the associated English nouns when shown the appropriate QV on two successive random presentations of the stimuli. Both types of stimuli were videotaped as in the earlier experiment, at the same rate and with the same intervals for recall. The auditory sequences were spoken by a female assistant, whose native language was English, whereas the visual stimuli were printed on index cards and held up by the same assistant. The recall procedure was the same as in the earlier experiments. As with the ASL stimuli, the instructions and communication took place in written form, in order to permit eventual comparisons between the performances of normal and deaf subjects in Experiment 2 . To provide comparability, the same procedures were followed in Experiment 4.

In Experiments 3 and 5, the seven four-letter English nouns, which were used as the to-be-recalled stimuli, made up the to-beremembered lists. The star suffix was used in these studies. The experimental design was the same as in the other three experiments, except that instead of being required to recall the stimuli associated with the presented stimuli, the subjects were asked to recall the seven English nouns presented. These stimuli were arranged in the same design that was used in Experiments 1, 2, and 4. The suffixes were presented in the five previously used formats.

\section{Results and Discussion}

The results of Experiments 2 and 3, which involved, respectively, visual QVs recoded into words and words alone, were analyzed first. They are shown in Table 2.

The control conditions of both experiments show the typical $j$-shaped recall curve, with large primacy and a small amount of recency, usually found with visual stimuli.

Further analysis of these data includes a 2 (presentation format, QV vs. word) $\times 5$ (suffix) $\times 7$ (serial position) analysis of variance. The only significant effect was the uninteresting main effect of serial position $[F(6,112)=$ 92.36, $M S_{\mathrm{e}}=1.79 \mathrm{]}$. The lack of interaction of presentation format with any of the other variables shows a similar pattern of performance for QVs and words.

Planned Dunnett tests, using the error term for the presentation format $\times$ suffix $\times$ serial position interaction $(\mathrm{C}-\mathrm{E}=.83)$, further clarify the data and show significance for the printed suffix at Position 5 in the QV study and at Positions 5 and 7 in the word study. These effects, although produced by suffixes in the same format as the sequence, are small. Moreover, although suffix effects of this type occasionally occur with visual stimuli, the effects are different from the major suffix effects reported with standard auditory stimuli.

Thus, it appears that the results of Experiments 2 and 3 are very similar to each other with respect to both the general shape of the serial recall data and the pattern of suffix effects, which leads to the conclusion that recoding is not an important variable in these effects at least in the visual modality.

The results of Experiments 4 and 5 can be seen in Table 3 . Examination of the data in both experiments shows

Table 2

Mean Number of Correct Responses as a Function of Serial Position and Sufrix Condition in Experiments 2 and 3, in Which Visual "Quasivocables" and Words Were Presented, Respectively

\begin{tabular}{lccccccc}
\hline \multirow{7}{*}{$\begin{array}{c}\text { Suffix } \\
\text { Condition }\end{array}$} & 1 & 2 & 3 & 4 & 5 & 6 & 7 \\
\hline & \multicolumn{7}{c}{ Serial Position } \\
Control & 5.87 & 5.53 & 4.67 & 4.40 & 3.40 & 1.53 & 2.80 \\
ASL & 5.60 & 5.00 & 4.13 & 4.00 & 3.40 & 2.13 & 2.53 \\
Spoken & 6.07 & 5.40 & 4.67 & 3.53 & 3.20 & 2.20 & 2.27 \\
Mouthed & 5.80 & 5.53 & 4.40 & 3.73 & 3.07 & 2.20 & 2.00 \\
Printed & 5.53 & 4.87 & 3.93 & 3.80 & $2.20^{*}$ & 1.80 & 2.27 \\
& & & Word & & & \\
Control & 6.60 & 5.87 & 5.87 & 4.73 & 4.47 & 3.07 & 3.73 \\
ASL & 6.13 & 5.66 & 4.93 & 4.06 & 3.33 & 3.13 & 3.67 \\
Spoken & 6.26 & 6.06 & 5.60 & 4.93 & 3.73 & 3.40 & 3.33 \\
Mouthed & 6.40 & 6.13 & 5.27 & 4.33 & 4.20 & 3.40 & 3.73 \\
Printed & 6.20 & 5.80 & 5.46 & 4.80 & $2.80^{*}$ & 2.80 & $2.80^{*}$ \\
\hline Note-Max & & & & & & & \\
\end{tabular}

Note-Maximum performance is 7 in each serial position. *Dunnett test significant $(\mathrm{C}-\mathrm{E}=.83)$. 
recency in the control condition, according to a measure that will be called the recency measure (RM). This measure, calculated by subtracting performance at Position 6 from that at Position 7, is significant for both the QV and the word conditions $[t s(14)=6.16$ and 6.28 , respectively]. Contrary to the predictions of Shand and Klima (1981), with respect to comparisons between the results in Experiments 4 and 5, there is no significant difference in size of the RMs. In fact, there is a tendency toward a reversal, with the size of the RM being larger for the Type 2 recoding task than for the Type 1 recoding task. This nonsignificant reversal is similar to results previously found with second language stimuli in our laboratory (Manning et al., 1989).

As with Experiments 2 and 3, a $2 \times 5 \times 7$ analysis of variance was performed on the data from Experiments 4 and 5 . In this analysis, the main effects of suffix $\left[F(4,112)=6.31, M S_{\mathrm{e}}=2.90\right]$ and serial position $\left[F(6,168)=95.74, M S_{\mathrm{e}}=3.12\right]$ were significant, due, respectively, to the usual effect of an auditory suffix in reducing performance and the usual serial position irregularities when serial position data are summed over conditions.

In addition, the effects of suffix $\times$ serial position $\left[F(24,672)=5.87, M S_{\mathrm{e}}=1.06\right]$, serial position $\times$ presentation format $\left[F(6,168)=2.24, M S_{\mathrm{e}}=3.12\right]$, and presentation format $\times$ serial position $\times$ suffix $[F(24,672)=$ $1.58, M S_{\mathrm{e}}=1.06$ ] were reliable. The sources of these significant interactions can be seen in Table 3 to be due, in order, to the greater effect of the suffix at the end of the sequence (which is usual for auditory stimuli), to irregularities in the performance across serial positions for the QVs and for words summed over suffixes, and to an unpredicted (at least by Shand \& Klima, 1981), relatively greater suffix effect at the end of the sequence for QVs as compared with words.

Dunnett tests, using the presentation format $\times$ suffix $X$ serial position error term for the interaction $(\mathrm{C}-\mathrm{E}=$ .82), were performed. In Experiment 4, using QVs, they show a very large suffix effect at Position 7 with the

Table 3

Mean Number of Correct Responses as a Function of Serial Position and Suffix Condition in Experiments 4 and 5, in Which Auditory "Quasivocables" and Words Were Presented, Respectively

\begin{tabular}{|c|c|c|c|c|c|c|c|}
\hline \multirow{2}{*}{$\begin{array}{c}\text { Suffix } \\
\text { Condition }\end{array}$} & \multicolumn{7}{|c|}{ Serial Position } \\
\hline & 1 & 2 & 3 & 4 & 5 & 6 & 7 \\
\hline \multicolumn{8}{|c|}{ QV } \\
\hline Control & 4.73 & 4.47 & 3.40 & 2.73 & 1.27 & 2.07 & 5.40 \\
\hline ASL & 5.53 & 4.93 & 4.20 & 2.60 & 1.67 & 1.47 & $4.13^{*}$ \\
\hline Spoken & 5.53 & 4.20 & 3.80 & 1.93 & 1.07 & $0.73 *$ & $2.13^{*}$ \\
\hline Mouthed & 4.73 & 4.53 & 3.40 & 2.47 & 1.27 & 1.33 & $4.53^{*}$ \\
\hline Printed & 5.80 & 5.00 & 3.87 & 2.47 & 1.00 & $0.93 *$ & 4.60 \\
\hline \multicolumn{8}{|c|}{ Word } \\
\hline Control & 5.67 & 4.20 & 3.67 & 3.07 & 2.33 & 2.00 & 4.87 \\
\hline ASL & 5.40 & 4.86 & 3.87 & 3.13 & 2.07 & 2.40 & 5.00 \\
\hline Spoken & 5.33 & 4.67 & 3.33 & 2.67 & 2.27 & 1.80 & $2.20^{*}$ \\
\hline Mouthed & 5.33 & 4.87 & 3.60 & 3.40 & 2.73 & 2.33 & $3.86^{*}$ \\
\hline Printed & 5.60 & 5.20 & 4.20 & 3.53 & 2.13 & 2.40 & 5.27 \\
\hline
\end{tabular}

Note-Maximum performance is 7 in each serial position. *Dunnett test significant $(\mathrm{C}-\mathrm{E}=.82)$. spoken suffix, and much smaller but significant effects at Position 7 for mouthed and ASL suffixes. The ASL suffix effect at Position 7 is hard to explain. Probably random, but also present, is a significant effect at Position 6 for the printed suffix. In Experiment 5, using words, the Dunnett tests show a large significant effect at Position 7 for the spoken suffix and a smaller significant effect for mouthed suffixes. The results with the auditory and mouthed suffixes in both studies are consistent with the literature in this area although the mouthed suffix in Experiment 4 shows a somewhat smaller effect than expected.

The data in Experiments 4 and 5 show a nonsignificant difference between what would be considered Type 1 recoding and forced Type 2 recoding in the amount of recency present. In addition, the latter situation actually shows greater recency. Suffix effects are also larger in the Type 2 recoding task than in the Type 1 task. The reversal with the suffix effects is significant. Both of these effects are the opposite of the predictions of Shand and Klima (1981) that suffix effects will be greater in a primary linguistic code than in another presentation format. Combined with the other findings in this study, these results suggest that recoding is not relevant to recency and suffix effects.

\section{GENERAL DISCUSSION}

In these experiments, we attempted to clarify three issues with respect to recency and suffix effects. The first involves the puzzling results reported by Campbell et al. (1983) with ASL stimuli in normal subjects not fluent in ASL. The second is the role of recoding in the recency and suffix effects, and the third involves the implications of our findings for the theory of Shand and Klima (1981) and other theories in the area.

With respect to the first issue, we have failed to replicate Campbell et al. (1983). Apparently, ASL stimuli, when taught to normal hearing subjects, act very much as other visual stimuli and do not produce recency and suffix effects similar to those produced by auditory stimuli. Campbell et al.'s finding of recency was inconsistent with most other work involving visual stimuli, and thus the nonreplication may simplify the development of new theories. It should also be noted that our failure to replicate the recency obtained by Campbell et al. (1983) is another example of recency and suffix effects' not occurring with changing-state visual stimuli. The ASL stimuli in this study are clearly changing state, as contrasted with static, and recency is not present.

As for the role of recoding, we believe that the definitions in the introduction have clarified this concept. Such clarification was needed to test the theory of Shand and Klima (1981). As for the data, it is apparent that Type 2 recoding, which is consistent with the definitions of Shand and Klima, does not lead to lesser recency than does Type 1. This fact was previously suggested in research with second and unknown languages in this laboratory (Manning et al., 1989). However, the comparisons of 
the recency shown in Experiment 4 with that in Experiment 5 provide strong direct evidence. Subjects were forced in Experiment 4 to translate a within-modality, nonlinguistic stimulus into a linguistic stimulus, and recency was slightly greater than in Experiment 5, which involves Type 1 recoding. In the language of Shand and Klima, the recall of primary linguistic stimuli was not better than that of non-primary linguistic stimuli. This provides a direct contradiction to the primary linguistic hypothesis.

As for suffix effects, they appear to be present for Type 2 recoding, and in Experiment 4, both terminal and overall suffix effects were significantly larger than in Experiment 5 . Thus, rather than reducing suffix effects, this type of "recoding" may enhance them, perhaps because the relative difficulty of the task makes it more susceptible to interference and thus leads to the larger suffix effects. This finding also contradicts the theory of Shand and Klima (1981).

What, then, do these experiments say about the sources of recency and suffix effects? What seems evident is that, in this set of studies, the modality or presentation format of the stimulus presented by the experimenter determines the presence or absence of recency and suffix effects, rather than anything relating to recoding or primary linguistic variables. In an attempt to follow Shand and Klima (1981), we developed the concept of Type 2 recoding. In the present experiments, as well as others reported, we found no evidence that this type of recoding had any relation to reduced recency or suffix effects.

As for other issues raised by this experiment, although the results are consistent with the view that stimuli that involve Type 3 recoding do not result in recency or suffix effects, other data suggest that this may not always be the case. There are considerable data showing the presence of recency and suffix effects in lipread or mouthed stimuli (e.g., Campbell \& Dodd, 1980; Campbell et al., 1988; Greene \& Crowder, 1984). Shand and Klima (1981) make some attempt to tie these findings to the primary linguistic hypothesis. However, if Type 1 recoding and primary linguistic qualities are essential for enhanced recency, lipread and mouthed stimuli seem not to fit the Shand and Klima conceptualization. They also cause difficulties for any recoding view, since they appear to fit the definition of Type 3 recoding. Campbell and Dodd (1980) reported that subjects watching mouthed stimuli with a white noise background claimed to have heard them. Furthermore, work in this laboratory (Shofner, 1988) has shown that there is a close (although not perfect) relation between the confusability of lipread and that of auditory stimuli. These data, combined with other obvious links between speech and lipreading and articulation, all of which are involved in the production and perception of language (see Nairne, 1988, for a discussion of some possibie links between these presentation formats), suggest the strong likelihood of an auditory component in the representations produced by such stimuli. The results with lipread stimuli also cause problems for any modality-specific theory, for they are clearly visual.

What, then, should be said about current theories that relate to the source of recency, modality effects, and suffix effects? Although the research presented in the present paper does not bear on these views directly, a summary may serve to place this research in the context of ongoing work.

Glenberg and co-workers (e.g., Glenberg, 1984; Glenberg \& Fernandez, 1988; Glenberg \& Swanson, 1986) have proposed a temporal distinctiveness hypothesis, which they have applied mainly to the continuous distractor paradigm. In this paradigm, stimuli are interspersed with distractor activities several seconds in length. The interval between the final item and recall is usually also followed by a distractor task. Since distractor tasks are generally several seconds in length, the occurrence of recency, modality, and suffix effects in this paradigm is inconsistent both with the original sensory trace theory of Crowder and Morton (1969) and with more recent revisions of this viewpoint (e.g., Greene \& Crowder, 1984). This is because the obtained modality effects persist over long periods of time, whereas sensory traces are hypothesized not to (Greene \& Crowder, 1986).

To explain findings in the continuous distractor paradigm, Glenberg (e.g., Glenberg \& Swanson, 1986) proposes that items are coded with modality-specific temporal cues. Recall involves the scanning of search sets that are larger and have a coarser grain for visual than for auditory stimuli. This results in less temporal discriminability for the visual stimuli, lowering the probability of correct sampling of items for the final position, and reducing the correct recall of more recent visual as compared with auditory items.

This view has been challenged by Crowder and Greene (1987), who asked subjects to estimate which of two adjacent time intervals was longer. Performance was no better when stimuli were read aloud than when they were read silently. Greene and Crowder (1988) also report other research that questions the greater temporal distinctiveness of auditory as compared with visual stimuli.

However, although temporal distinctiveness seems not to explain the findings in this area, other current views of the source of modality, recency, and suffix effects are partially related to the work of Glenberg (e.g., Glenberg \& Swanson, 1986) in that they include hypotheses ascribing these findings to final item distinctiveness, in various presentation formats and/or experimental paradigms (e.g., Gardiner, 1983; Manning \& Robinson, in press; Nairne \& McNabb, 1985; Routh \& Frosdick, 1978). We are currently pursuing a version of this viewpoint.

The idea that final-item distinctiveness increases recency and decreases suffix effects is suggested by Salter (1975) in research involving the substitution of an alphabetic character for a final digit in auditorily presented sequences of digits, and by Routh and Frosdick (1978) in a similar design in which subjects were given both auditorily and 
visually presented lists. Both studies found recency that was virtually immune to the effects of a suffix. In the latter study, modality effects were also eliminated, thus suggesting that if final-item distinctiveness is sufficient, recency will both be strengthened and be present regardless of presentation modality.

The other side of this final-item distinctiveness story predicts that auditory recency and suffix effects will be diminished if final-item distinctiveness is lessened. Just such an effect has been found in studies in which auditory confusability is increased (e.g., Darwin \& Baddeley, 1974; Drenowski, 1980; Manning, 1984; Manning \& Robinson, in press). These findings are predicted on the basis that when stimuli are auditorily confusable, it is harder to discriminate a final item from earlier items.

Related at least partially to the final-item distinctiveness hypothesis, another viewpoint, suggested by Nairne (1988), involves a framework based on modality-dependent and modality-independent variables. This framework suggests explanations for why nonauditory linguistically based stimuli, such as lipread and mouthed stimuli, produce recency and suffix effects, as well as why "nonnormal" visual stimuli, such as nonsense shapes, have also produced such results. The former stimuli are hypothesized to be involved in language production, whereas the latter set have greater salience and protracted encoding that may lead to greater distinctiveness.

However, experiments reported in this paper do not provide direct tests of any of the more recent theories discussed above, including the final-item distinctiveness theory. Instead, as a result of this research, we wish to conclude that newly learned ASL apparently does not lead to recency and suffix effects in normal hearing subjects. It seems clear that stimuli in a primary linguistic mode of a subject do not lead to enhanced recency or suffix effects when compared to stimuli that are not in such a mode. Modifications of the primary linguistic theory, which involve recoding of various types, do not account for the data either. Thus, we believe that the experiments presented here have eliminated both the primary linguistic hypothesis and recoding as relevant to recency, suffix effects, and modality effects. Our data should be useful in eliminating one more provocative but apparently incorrect theory in this complex area that clearly needs further research for an adequate theory to be developed. Some of the current research in this area may lead to just such a theory.

\section{REFERENCES}

CAMPbell, R., \& DodD, B. (1980). Hearing by eye. Quarterly Journal of Experimental Psychology, 32, 85-99.

CAMPBell, R., DodD, B., \& Brasher, J. (1983). The sources of visual recency: Movement and language in serial recall. Quarterly Journal of Experimental Psychology, 35A, 571-587.

Camprell, R., Garwood, J., \& Rosen, S. (1988). Adding sound to lipread lists: The effects on serial recall of adding an auditory pulse train and a pure tone to silently lipread lists. Memory \& Cognition, 16, 210-219.
Conen, G. (1972). Serial position efffects in the recall of picture se quences. Quarterly Journal of Experimental Psychology, 24, 41-47.

ConRad, R. (1964). Acoustic confusions in immediate memory. British Joumal of Psychology, 55, 75-84.

Crowder, R. G. (1986). Auditory and temporal factors in the modality effect. Journal of Experimental Psychology: Human Memory \& Cognition, 12, 268-278.

Crowder, R. G., \& GreEne, R. L. (1987). On the remembrance of things past: The irregular list technique. Journal of Experimental $P_{\text {sy- }}$ chology: General, 116, 265-278.

Crowder, R. G., \& Morton, J. (1969). Precategorical acoustic storage (PAS). Perception \& Psychophysics, 5, 365-373.

DARWIN, C. J., \& BADDELEY, A. D. (1974). Acoustic memory and the perception of speech. Cognitive Psychology, 6, 41-60.

DREWNOWSKI, A. (1980). Memory functions for vowels and consonants: A reinterpretation of acoustic similarity effects. Journal of Verbal Learning \& Verbal Behavior, 19, 176-193.

Gardiner, J. M. (1983). On recency and echoic memory. Philosophical Transactions of the Royal Society of London, 302B, 267-282.

Glenberg, A. M. (1984). A retrieval account of the long-term modality effect. Journal of Experimental Psychology: Learning, Memory, \& Cognition, 10, 16-31.

GlenberG, A., \& Fernandez, A. (1988). Evidence for auditory temporal distinctiveness: Modality effects in order and frequency judgments. Journal of Experimental Psychology: Learning, Memory, \& Cognition, 14, 728-739.

Glenberg, A., \& SWAnson, N. G. (1986). A temporal distinctiveness model of recency and modality effects. Journal of Experimental Psychology: Learning, Memory, \& Cognition, 12, 3-15.

GreENE, R. L. (1987). Stimulus suffixes and visual presentation. Memory \& Cognition, 15, 497-503.

Greene, R. L., \& Crowder, R. G. (1984). Modality and suffix effects in the absence of auditory stimulation. Joumal of Verbal Learning \& Verbal Behavior, 23, 371-382.

Greene, R. L., \& Crowder, R. G. (1986). Recency effects in delayed recall of mouthed stimuli. Memory \& Cognition, 14, 355-360.

Greene, R. L., \& Crowder, R. G. (1988). Memory for serial position: Effects of spacing, vocalization, and stimulus suffixes. Journal of Experimental Psychology: Learning, Memory, \& Cognition, 14, 740-748.

Krakow, R. A., \& Hanson, V. L. (1985). Deaf signers and serial recall in the visual modality: Memory for signs, fingerspelling, and print. Memory \& Cognition, 13, 265-272.

Manning, S. K. (1980). Tactual and visual suffix effects. Quarterly Journal of Experimental Psychology, 32, 257-267.

MANNING, S. K. (1984). Effects of difficulty variables and type of suffix on serial recall. American Journal of Psychology, 97, 71-87.

MANNing, S. K. (1987). Attentional control of visual suffix effects. Bulletin of the Psychonomic Society, 25, 423-426.

MANning, S. K., \& GMuer, B. A. (1985). Visual suffix effects on the Optacon: A test of changing state, primary linguistic, and attentional theories. Bulletin of the Psychonomic Society, 23, 1-4.

ManNing, S. K., \& RoBinson, I. I. (in press). Recency and suffix effects as a function of stimulus similarity and set size. American Journal of Psychology.

MANNING, S. K., \& SChreIER, H. (1988). Recency and suffix effects in pictures as a function of recall method. American Journal of Psychology, 101, 97-109.

Manning, S. K., Silverstein, B., \& Schreier, H. (1989). Recency and suffix effects in first, second, and unknown languages: $A$ test of the primary linguistic hypothesis. American Journal of Psychology, 102, 385-395.

NAIRNE, J. S. (1988). A framework for interpreting recency effects in immediate serial recall. Memory \& Cognition, 16, 343-352.

NAIRNE, J. S., \& MCNABb, W. L. (1985). More modality effects in the absence of sound. Journal of Experimental Psychology: Learming, Memory, \& Cognition, 11, 596-604.

PaIvio, A. (1969). Mental imagery in associative learning and memory. Psychological Review, 76, 241-263.

PaIvio, A. (1971). Imagery and verbal processes. New York: Holt, Rinehart \& Winston. 
Paivio, A., Rogers, T. B., Smythe, P. C. (1968). Why are pictures easier to recall than words? Psychonomic Science, 11, 137-138.

Routh, D. A., \& Frosdick, R. M. (1978). The basis and implications of the restoration of a recency effect in immediate serial recall. Quarterly Journal of Experimental Psychology, 30, 201-220.

SALTER, D. (1975). Maintaining recency despite a stimulus suffix. Quarterly Joumal of Experimental Psychology, 27, 433-443.

Shand, M. A., \& Elman, J. (1982). Recency effects for native and non-native language presentations. In Linguistic notes from La Jolla: Working papers of the Department of Linguistics (No. 11, pp. 6875). La Jolla, CA: University of California, San Diego.

Shand, M. A., Klima, E. S. (1981). Nonauditory suffix effects in congenitally deaf signers of American Sign Language. Journal of $E x$ perimental Psychology: Human Learning \& Memory, 7, 464-474.
SHOFNER, E. (1988). Similarity ratings and confusability of lipread consonants: Auditory or visual? Unpublished master's thesis, Hunter College of the City University of New York

Spoehr, K. T., Corin, W. J. (1978). The stimulus suffix effect as a memory coding phenomenon. Memory \& Cognition, 6, 583-589.

TartTer, V. C., \& Shand, M. A. (1980). Pig Latin remembered: Test of a recoding explanation for modality/recency effects in short-term recall. Journal of the Acoustical Society of America, 68A, S48.

(Manuscript received June 16, 1988; revision accepted for publication May 5, 1989.)

\section{Forthcoming Memory \& Cognition Articles}

The following is list of forthcoming Memory \& Cognition articles that are currently in press. They are given in approximate order of acceptance. Each entry includes the name and address of the author with whom to communicate for further prepublication information.

"Cognitive representation of linear motion: Possible direction and gravity effects in judged displacement' by T. L. Hubbard (Dept. Psychol., Eastern Oregon State Coll., 8th and K Avenues, LaGrande, OR 97850)

"Semantic priming in the pronunciation task: The role of prospective prime-generated expectancies"' by D. E. Keefe \& J. H. Neely (J.H.N., Dept. Psychol., State Univ. of New York, Albany, NY 12222)

"Reinstating study context produces unconscious influences of memory" by S. W. Allen \& L. L. Jacoby (L.L.J., Dept. Psychol., McMaster Univ., Hamilton, Ont. L8S 4K1, Canada)

"Lexical processing in a non-native language: Effects of language proficiency and learning strategy" by H.-C. Chen (Dept. Psychol., Chinese Univ. of Hong Kong, Shatin, NT, Hong Kong)

“Typicality and reading fallacies" by E. B. Shafir, E. E. Smith, \& D. N. Osherson (E.B.S., Dept. Psychol., Green Hall, Princeton Univ., Princeton, NJ 08544)

"Tracing the footsteps of Sherlock Holmes: Cognitive representations of hypothesis testing' by L. R. Van Wallendael \& R. Hastie (L.R.V.W., Dept. Psychol., Univ. North Carolina, Charlotte, NC 28223)

"The generality of mental addition models: Simple and complex addition in a decision-production task" by L. Timmers \& W. Claeys (L.T., Dept. Psychol., Univ. Louvain, Tiensestraat 102, B-3000 Louvain, Belgium)

"Resolving semantically induced tip-of-the-tongue states for proper nouns" by T. Brennen, T. Baguley, J. Bright, \& V. Bruce (V.B., Dept. Psychol., Univ. Nottingham, University Park, Nottingham NG7 2RD, U.K.)

"Event-related brain potentials dissociate repetition effects of high- and low-frequency words"' by M. D. Rugg (Dept. Psychol., Univ. St. Andrews, St. Andrews, Fife KY16 9JU, U.K.)

"Interactions between sentence context and word frequency in event-related brain potentials" by C. Van Petten \& M. Kutas (C. V.P., Dept. Neurosci., M-008, Univ. California, San Diego, La Jolla, CA 92093)
"A feature model of immediate memory" by J. S. Nairne (Dept. Psychol. Sci., Purdue Univ., West Lafayette, IN 47907)

"Medical expertise as a function of task difficulty" by V. L. Patel, G. J. Groen, \& J. F. Arocha (V.L.P., Cog. Studies in Med., Ctr. for Med. Ed., McGill Univ., 3655 Drummond St., Rm. 529, Montreal, PQ H3G 1Y6, Canada)

"The contribution of task-related factors to ERP-repetition effects at short and long lags" by S. Bentin \& B.-S. Peled (S.B., Dept. Neurosciences, M-008, Univ. California, San Diego, La Jolla, CA 92093)

"Disambiguation by community membership" by R. J. Gerrig \& M. L. Littman (R.J.G., Dept. Psychol., Yale Univ., P.O. Box 11A Yale Sta., New Haven, CT 06520-7447)

"Converging operations on a basic level in event taxonomies" by M. W. Morris \& G. L. Murphy (G.L.M., Walter S. Hunter Lab. Psychol., Brown Univ., Providence, RI 02912)

"Orthographic onsets and rimes as functional units of reading" by J. A. Bowey (Dept. Psychol., Univ. Queensland, St. Lucia, Queensland 4067, Australia)

"Implicit associative responses influence encoding in memory" by D. J. Bryant (Dept. Psychol., Jordan Hall, Bldg. 420, Stanford Univ., Stanford, CA 94305)

"Vivid memories of emotional events: The accuracy of remembered minutiae' by F. Heuer \& D. Reisberg (D.R., Dept. Psychol., Reed Coll., Portland, OR 97202)

"Processing speed and mental retardation: Deadline procedures indicate fixed and adjustable limitations' by $N$. Brewer $\&$ G. A. Smith (N.B., National Police Research Unit, P.O. Box 370, Marden, South Australia 5070, Australia)

"The effect of context on discrimination and bias in recognition memory for pictures and words" by K. Feenan \& J. G. Snodgrass (J.G.S., Dept. Psychol., New York Univ., 6 Washington Pl., Rm. 857, New York, NY 1003)

"The relation between syllable number and visual complexity in the acquisition of word meanings' by $\mathbf{M}$. H. Kelley, K. Springer, \& F. C. Keil (M.H.K., Dept. Psychol, Univ. Pennsylvania, 3815 Walnut St., Philadelphia, PA 19104) 